\title{
ÍNDICE DE SUSTENTABILIDADE DO MUNICÍPIO DE BARRA DO CHOÇA-BA
}

\section{SUSTAINABILITY INDEX OF BARRA DO CHOÇA \\ MUNICIPAL DISTRICT - BAHIA}

\author{
Celeste Dias Amorim \\ Universidade Estadual de Santa Cruz - Ilhéus - BA - Brasil \\ George Nathan Souza Brito \\ Universidade Estadual de Santa Cruz - Ilhéus - BA - Brasil \\ Milton Ferreira da Silva Júnior \\ Universidade Estadual de Santa Cruz - Ilhéus - BA - Brasil \\ Universidade Federal do Sul da Bahia - Itabuna - BA - Brasil
}

Resumo : Este estudo objetivou determinar o índice de sustentabilidade do Município de Barra do Choça, Bahia. Para atingir essa meta, optou-se pela utilização do método do Gráfico Radar, no qual, por meio do cálculo da área dos triângulos formados pelos vértices de cada variável, foi possível encontrar um índice pela soma destes vértices. Ao mesmo tempo, o método possibilita a comparação das áreas obtidas, pois, quanto maior a área do triângulo formado, maior a sustentabilidade do indicador, permitindo a relação entre todas as variáveis pesquisadas. A base de dados foi composta por pesquisas de indicadores já consolidados na literatura, ou seja, a dimensão econômica, social e ambiental. Assim, optou-se pela seleção de três indicadores para cada dimensão, tendo como padrão a sua mensuração no ano de 2010. Essa metodologia proporcionou maior clareza na representação dos resultados, pois, por meio de diferentes indicadores, foi possível mensurar a sustentabilidade, além disso, foi de fácil aplicabilidade. Os índices das dimensões revelaram que a social obteve melhor desempenho do que a econômica e ambiental, nas quais seus indicadores apontam resultados semelhantes. Concluiu-se que o município apresentou bom Índice de Sustentabilidade. Espera-se que o estudo sirva para embasar as tomadas de decisões visando à melhoria da sustentabilidade municipal.

Palavras-chave: Dimensão Econômica. Dimensão Social. Dimensão Ambiental. Gráfico Radar. Indicadores.

Abstract: This study aimed to determine the sustainability index for the Barra do Choça municipal district, Bahia. To achieve this goal it was decided to use the Radar-Graph 
method in which, by calculating the area of the triangles formed by the vertices of each variable, was possible to find an index by the sum of these vertices. At the same time, the method enables comparison of the areas obtained, because the higher the triangle area formed greater sustainability of the indicator, allowing the relationship between all the variables investigated. The database consisted of indicators of research already established in the literature, the economic, social and environmental dimensions. So we opted for the selection of three indicators for each dimension, having as its measurement standard in 2010. This methodology provided greater clarity in the presentation of the results, because through different indicators could measure the sustainability, beyond that was applied easily. The dimensions indices demonstrated that the social performance obtained was better than the economic and environmental, in which their indicators showed similar results. It was concluded that the municipal district had good Sustainability Index. It is hoped that the study serves to support decision-making aimed at improving municipal sustainability.

Keywords: Economic Dimension. Social Dimension. Environmental Dimension. RadarGraphic. Indicators.

\section{Introdução}

O Município de Barra do Choça, localizado no sudoeste da Bahia, no século XIX era uma fazenda utilizada como ponto de apoio para tropeiros, boiadeiros e viajantes. Depois, passou a distrito e, na década de 1960, foi emancipada e teve seu pico de expansão na década de 1970 por meio da implantação da cafeicultura. Esse período marcou decisivamente a estrutura do campo e da cidade e o modo de vida da sua população urbana e rural, sobretudo, impactou no crescimento populacional e em mudanças socioeconômicas. Pode-se destacar que a cultura do café trouxe ao município riqueza, mas também miséria, além de problemas ambientais (ROCHA, 2011). A publicação da Lei $n^{\circ}$ $173 / 10$, que estabeleceu a diferenciação de tratamento entre as microempresas e as empresas de pequeno porte do município (BARRA DO CHOÇA, 2010), impulsionou mudanças na atividade econômica, no comércio e no setor industrial.

Quanto a esta mudança na configuração local, Peruzzo e Volpato (2009, p. 8) dizem que "o local é um espaço que apresenta certa unidade, certa especificidade, mas que pode se modificar, como também se modificam seus fluxos, ou seja, possuem características que podem ser transitórias: em dado momento apresentam uma unicidade, em outro momento, não mais". Os dados, assim que apresentam ou 
demonstram a realidade local, podem se configurar como um indicador ou um conjunto de indicadores (inter)relacionados: um Índice.

Segundo Reed, Fraser e Dougill (2006), uma das formas de se compreender e monitorar o desenvolvimento sustentável está em estabelecer indicadores de sustentabilidade por meio de dados locais, no entanto os autores chamam a atenção pela maneira da coleta dos dados, pois ainda não se tem claro a melhor forma desta execução, o que torna conflitante o método de seleção dos indicadores. Assim, para eles, na escolha dos indicadores não se deve selecionar apenas aqueles relevantes para a população local, mas também se deve selecionar um método específico para recolher, interpretar e exibir os dados.

Para Bomfim (2013, p. 35-36) os objetivos de um indicador são:

a) definir ou monitorar a sustentabilidade de uma realidade;

b) facilitar o processo de tomada de decisão;

c) evidenciar, em tempo hábil, modificação significativa em um dado sistema;

d) caracterizar uma realidade, permitindo a regulação de sistemas integrados;

e) estabelecer restrições em função da determinação de padrões;

f) detectar os limites entre o colapso e a capacidade de manutenção de um sistema;

g) tornar perceptíveis as tendências e as vulnerabilidades;

h) sistematizar as informações, simplificando a interpretação de fenômenos complexos;

i) ajudar a identificar tendências e ações relevantes, bem como avaliar o progresso em direção a um objetivo;

j) prever o status do sistema, alertando para possíveis condições de risco;

k) detectar distúrbios que exijam o replanejamento; e,

l) medir o progresso em direção à sustentabilidade. 
Nesse caso, Reed, Fraser e Dougill (2006) dizem que os indicadores de sustentabilidade devem ir além de medir o progresso, eles podem e devem: estimular uma melhor compreensão dos problemas ambientais e sociais; facilitar a capacitação da comunidade e ajudar na formulação de políticas públicas.

Assim, estabelecer indicadores são métodos utilizados para "mensurar" a sustentabilidade. Nesse sentido, Passo (2008), Bonfim (2013) e Sattler (2013) apontam a sustentabilidade social, econômica, ecológica, espacial e cultural como dimensões do desenvolvimento sustentável (Quadro 1).

\section{Quadro 1. As cinco dimensões do desenvolvimento sustentável}

\begin{tabular}{|c|c|c|}
\hline Dimensão & Componentes & Objetivos \\
\hline $\begin{array}{l}\text { Sustentabilidade } \\
\text { Social }\end{array}$ & $\begin{array}{l}\text { - Criação de postos de trabalho que } \\
\text { permitam a obtenção de renda } \\
\text { individual adequada; } \\
\text { - Produção de bens dirigida; } \\
\text { - Prioritariamente às necessidades } \\
\text { básicas sociais. }\end{array}$ & $\begin{array}{l}\text { Redução das } \\
\text { desigualdades }\end{array}$ \\
\hline $\begin{array}{l}\text { Sustentabilidade } \\
\text { Econômica }\end{array}$ & $\begin{array}{l}\text { - Fluxo permanente de investimentos } \\
\text { públicos e privados; } \\
\text { - Manejo eficiente dos recursos; } \\
\text { - Absorção, pela empresa, dos custos } \\
\text { ambientais; } \\
\text { - Endogenização: contar com suas } \\
\text { forças. }\end{array}$ & $\begin{array}{l}\text { Aumento da } \\
\text { produção e da } \\
\text { riqueza social, sem } \\
\text { dependência externa }\end{array}$ \\
\hline $\begin{array}{l}\text { Sustentabilidade } \\
\text { Ecológica }\end{array}$ & $\begin{array}{l}\text { - Produzir respeitando os ciclos } \\
\text { ecológicos dos ecossistemas; } \\
\text { - Pendência no uso dos recursos } \\
\text { naturais; } \\
\text { - Prioridade à produção de biomassa e à } \\
\text { industrialização de insumos naturais } \\
\text { renováveis; } \\
\text { - Redução da intensidade energética e } \\
\text { - Tecnologias e processos produtivos de } \\
\text { - baixo índice de resíduos; } \\
\text { - Cuidados ambientais. }\end{array}$ & $\begin{array}{l}\text { Melhoria da qualidade } \\
\text { do meio ambiente e } \\
\text { preservação das } \\
\text { fontes de recursos } \\
\text { energéticos e naturais } \\
\text { para as próximas } \\
\text { gerações }\end{array}$ \\
\hline $\begin{array}{l}\text { Sustentabilidade } \\
\text { Espacial }\end{array}$ & $\begin{array}{l}\text { - Desconcentração especial (de } \\
\text { atividades e de população); } \\
\text { - Desconcentração/democratização do } \\
\text { poder local e regional; }\end{array}$ & $\begin{array}{l}\text { Evitar excesso de } \\
\text { aglomerações }\end{array}$ \\
\hline
\end{tabular}




\begin{tabular}{|c|c|c|}
\hline & $\begin{array}{l}\text { - Relação cidade/campo equilibrada } \\
\text { (benefícios centrípetos). }\end{array}$ & \\
\hline $\begin{array}{l}\text { Sustentabilidade } \\
\text { Cultural }\end{array}$ & $\begin{array}{l}\text { - Soluções adaptadas a cada } \\
\text { ecossistema; } \\
\text { - Respeito à formação cultural } \\
\text { comunitária. }\end{array}$ & $\begin{array}{l}\text { Evitar conflitos } \\
\text { culturais com } \\
\text { potencial regressivo }\end{array}$ \\
\hline
\end{tabular}

Fonte: Passo (2008) e Bomfim (2013).

De acordo com Bomfim (2013), os indicadores têm direção e magnitude, podendo ser expressos em escala ou vetor, o que possibilita sua representação gráfica, ou seja, demonstrar a visualização de uma realidade ou uma projeção futura por meio da utilização de indicadores expressos na forma de vetores, grandeza e direção de uma maneira gráfica. Por outro lado, a complexidade em mensurar a sustentabilidade de diferentes aspectos de uma ou mais dimensões tornou-se um desafio para diversos pesquisadores que, segundo Bomfim (2013), é devido ao número de informações e variáveis. Nesse contexto, Daniel et al. (2001) propõe uma ferramenta metodológica de mensuração da sustentabilidade, sintetizando diversos indicadores em um índice, neste caso, o índice de sustentabilidade.

Diante o exposto, objetivou-se, neste estudo, determinar o índice de sustentabilidade do Município de Barra do Choça por meio do método desenvolvido por Daniel et al. (2001), com a representação do produto em um gráfico tipo radar.

\section{Metodologia}

\section{1 Caracterização da área amostral}

O Município de Barra do Choça, locus desta pesquisa, sob a altitude 847 m e Coordenadas Geográficas Latitude Sul 14 ${ }^{\circ} 52^{\prime} 52^{\prime \prime}$ e Longitude Oeste $40^{\circ} 34^{\prime} 46^{\prime \prime}$, faz parte do Território de Identidade Vitória da Conquista, que é formado por 20 municípios (Anagé, Aracatu, Barra do Choça, Belo Campo, Bom Jesus da Serra, Caetanos, Cândido Sales, Caraíbas, Condeúba, Cordeiros, Encruzilhada, Guajeru, Jacaraci, Licínio de Almeida, Maetinga, Mirante, Mortugaba, Piripá, Planalto, Poções, Presidente Jânio Quadros, Ribeirão do Largo, Tremedal e Vitória da 
Conquista) (SEI, 2012, 2013; IBGE, 2014). Sua localização no território de identidade está no perímetro de baixo índice de desenvolvimento social (Figura 1). 
Figura 1. Índice de desenvolvimento social do Território de Identidade Vitória da Conquista, Bahia

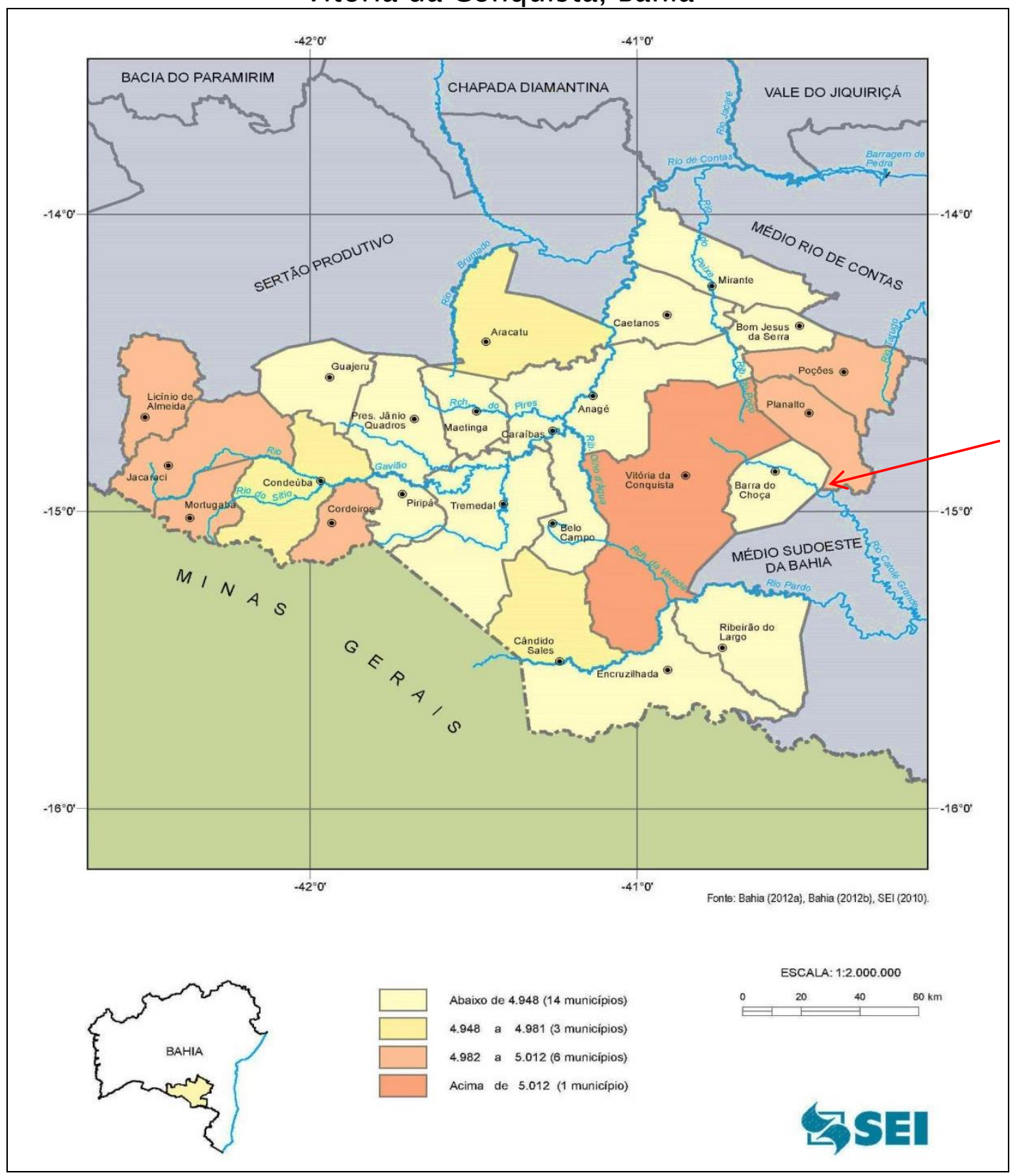

Fonte: SEI (2013).

Com área de $646,6 \mathrm{~km}^{2}$, Barra do Choça limita-se com os municípios de Caatiba, Itambé, Planalto e Vitória da Conquista, distando $532 \mathrm{~km}$ da capital do estado (SEI, 2012, 2013; IBGE, 2014). Segundo Soares e Rocha $(2010$, p. 141 ; 144) entre os municípios vizinhos, "era o que tinha o menor contingente populacional. Até 1970, o município contava com 8.953 hab, sendo que 83 \% moravam na zona rural" tendo, segundo as autoras, um crescimento demográfico de 326,3\% em 2010. 
Índice de sustentabilidade do Município de Barra do Choça-BA

Redes (St. Cruz Sul, Online), v. 21, n² 2, p. 87 - 106, maio/ago. 201694 
Em 2010, Barra do Choça apresentava uma densidade demográfica de $53,80 \mathrm{hab} / \mathrm{km}^{2}$ e uma população de 34.788 hab., distribuída entre zona urbana e rural, com 22.407 hab e 12.381 hab., respectivamente, havendo uma quase homogeneidade entre os sexos 17.553 masculino e 17.235 feminino (SEl, 2012, 2013; IBGE, 2014). Entre os 417 municípios baianos, Barra do Choça está situado entre os médios municípios, sendo o menor município Catolândia com 3.420 hab., e um dos 66 municípios com menos de 10 mil hab., e o maior, Salvador, com 2.883.672 hab (TRIBUNA FEIRENSE, 2013a, $2013 \mathrm{~b}$ ).

O Município Barra do Choça encontra-se inserido em uma região que possui as seguintes características: clima de subúmido a seco; período chuvoso entre os meses de novembro a janeiro; vegetação de Floresta Estacional Decidual/Floresta Estacional Semidecidual/Floresta Ombrófila Densa; solo Latossolos e Luvissolos; geomorfologia Patamares do Médio Rio de Contas, Piemonte Oriental do Planalto de Vitória da Conquista e Planalto dos Geraizinhos; geologia depósitos Eluvionares e Coluvionares, Gnaisses e Quartzo-Feldspático e ocorrências dos minerais: Água Mineral, Areia, Cianita e Mica (SEl, 2012, 2013).

A sua bacia hidrográfica é a do Rio Pardo, tendo como principais rios o Riacho Choça, Rio dos Canudos, Riacho Catolé Grande, Rio dos Monos e Ribeirão Água Fria. E como Espelhos d'água: Barragens de Água Fria I e II, Biquinha e Serra Preta (SEI, 2012, 2013; AMORIM, 2014). Um município rico em água, que promove o abastecimento para os municípios de Vitória da Conquista (sede e alguns distritos), Belo Campo (sede) e Planalto (sede). Essa importante contribuição é motivo de alguns conflitos, pois, uma vez que no Município de Barra do Choça se utiliza a irrigação para melhorar a produtividade da agricultura, uma de suas principais atividades, em períodos de estiagem, depara-se com a condição de ter que suspender a irrigação para priorizar o abastecimento de água potável ao seu município vizinho. Demonstra também preocupação quanto ao despejo de esgotos domésticos nos afluentes dos rios que abastecem a barragem de Água Fria I e II, pelo uso de fertilizantes e as formas inadequadas de descarte de vasilhas, bem como pela limpeza de equipamentos que podem contaminar o solo e, posteriormente, a água (BONFIM, 2012, AMORIM, 2014).

A atividade econômica, em 2010, centrava-se prioritariamente na 
administração pública e na agropecuária, extrativismo vegetal, caça e pesca, seguidos das atividades desenvolvidas no comércio, serviços, construção civil e indústria de transformação (SEl, 2012, 2013). Segundo o Serviço Brasileiro de Apoio às Micro e Pequenas Empresas SEBRAE/CNM (2014, s.p.), o município "é o maior exportador de café do Norte e Nordeste do Brasil. Mas foi com a implantação da Lei Geral da Micro e Pequena Empresa que outros setores produtivos cresceram, resultando na implantação do centro industrial [...] e a diversificação da economia, antes concentrada na cultura do café." Assim, por meio de políticas públicas, o município implantou a Agência de Desenvolvimento Econômico e Social, promovendo o crescimento de todos os segmentos econômicos, bem como o fortalecimento da cafeicultura e da bovinocultura com a pecuária leiteira. A participação popular no processo orçamentário é garantida pela Lei de Incentivo Fiscal. 
Nos últimos 40 anos, a área de floresta do município foi devastada pela monocultura do café (ROCHA, 2011) e, na última década, pela implantação do eucalipto, fatos estes preocupantes, principalmente no que se refere às nascentes. Assim, foram instituídos a Reserva Particular do Patrimônio Natural - RPPN Rio dos Monos e o Projeto de Lei/2012, que dispõe sobre o plantio e replantio para fins de uso doméstico ou industrial de eucalipto ou outras espécies exóticas, sendo esta ação estabelecida por iniciativa da participação popular em prol da preservação ambiental no município (AMORIM, 2012).

\begin{abstract}
Art. $7^{\circ}$ - Parágrafo único. Do investimento total aplicado no plantio de eucalipto e outras essências florestais exóticas, $5 \%$ (cinco por cento) dos recursos deverão ser destinados pelo investidor ao Fundo Municipal de Meio Ambiente, o qual deverá ser aplicado prioritariamente à recuperação de áreas de matas nativas e/ou matas ciliares local.

Art $2^{\circ}$ - A totalidade da extensão de terra a ser florestada com eucalipto ou outras essências florestais exóticas não deverá ultrapassar $10 \%$ (Dez por cento) da área total de cada propriedade (AMORIM, 2012, s.p.).
\end{abstract}

\title{
Amostragem e coleta dos dados
}

A seleção dos indicadores que formou a base de dados desta pesquisa foi composta por uma busca de indicadores já consolidados na literatura, precisamente pelos relatórios da Superintendência de Estudos Econômicos e Sociais da Bahia - SEI $(2012,2013)$ e do Programa das Nações Unidas para o Desenvolvimento - PNUD (2013). Posteriormente, esses indicadores foram agrupados observando as características das dimensões econômica, social e ambiental. Essas dimensões também foram utilizadas por Passos (2008), Sattler (2013) e Bomfim (2013).

Assim, optou-se pela seleção de três indicadores para cada dimensão, tendo como padrão a sua mensuração na literatura citada no ano de 2010 (Figura 2). 
Figura 2. Fluxograma das etapas e indicadores para determinar o Índice de Sustentabilidade

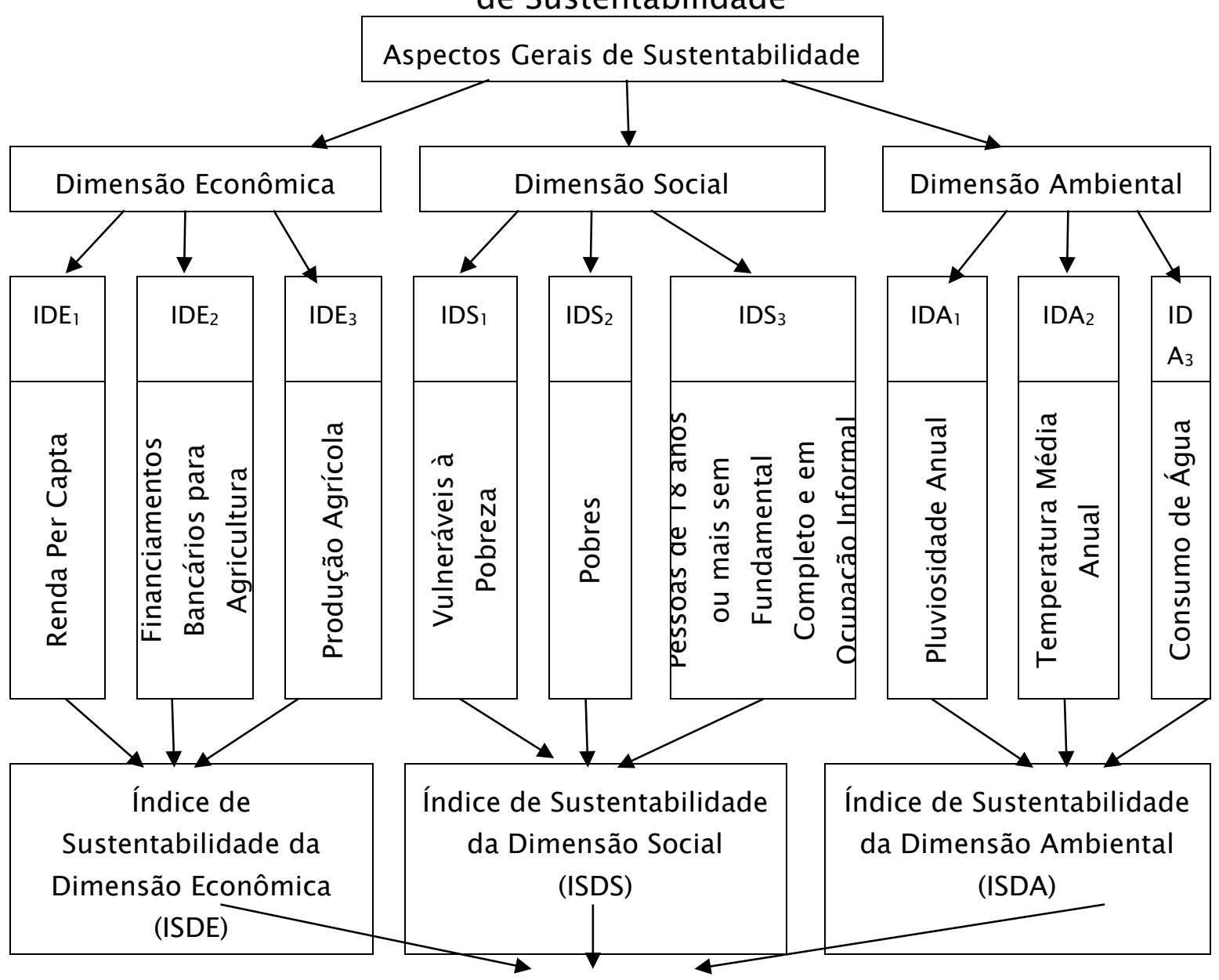

Índice de Sustentabilidade (IS) do Município de Barra do Choça

IDE = Indicador da Dimensão Econômica; IDS = Indicador da Dimensão Social; IDA = Indicador da Dimensão Ambiental

Fonte: elaborado a partir de Passos ([2010]) e Sattler (2013).

\section{0 método}

Segundo Bomfim (2014), a complexidade dos problemas que envolvem o desenvolvimento sustentável - DS requer a utilização de sistemas interligados ou indicadores inter-relacionados ou a agregação de diferentes indicadores em um ponto. No entanto, o autor aponta que, na prática, há alguns sistemas de indicadores que trabalham com o DS e na maioria destes em caráter experimental, desenvolvidos com o objetivo de compreender a sustentabilidade. 
Para atingir essa meta, neste estudo, optou-se pelo método aplicado com a utilização do gráfico radar proposto por Daniel et al. (2001), no qual cada eixo corresponde a um indicador, em que, por meio do cálculo da área dos triângulos formados pelos vértices de cada variável que compõem o conjunto da(s) dimensão(ões), é possível padronizá-los e a soma destes determinará um índice (Figura 3), ao tempo em que possibilita também a comparação entre as áreas. Nesse caso, quanto maior a área do triângulo formado pelos vértices do gráfico radar, maior a sustentabilidade do indicador ou quanto maior a área ocupada no gráfico radar, demonstrando um equilíbrio entre os indicadores no preenchimento, maior o índice de sustentabilidade da dimensão(ões) avaliada(s), além de favorecer uma dinâmica que possibilita a relação entre todas as variáveis pesquisadas (SATTLER, 2013; BONFIM, 2013).

Figura 3. Gráfico tipo radar utilizado para gerar um índice de sustentabilidade (IS), demonstrando a padronização que facilita a interpretação visual

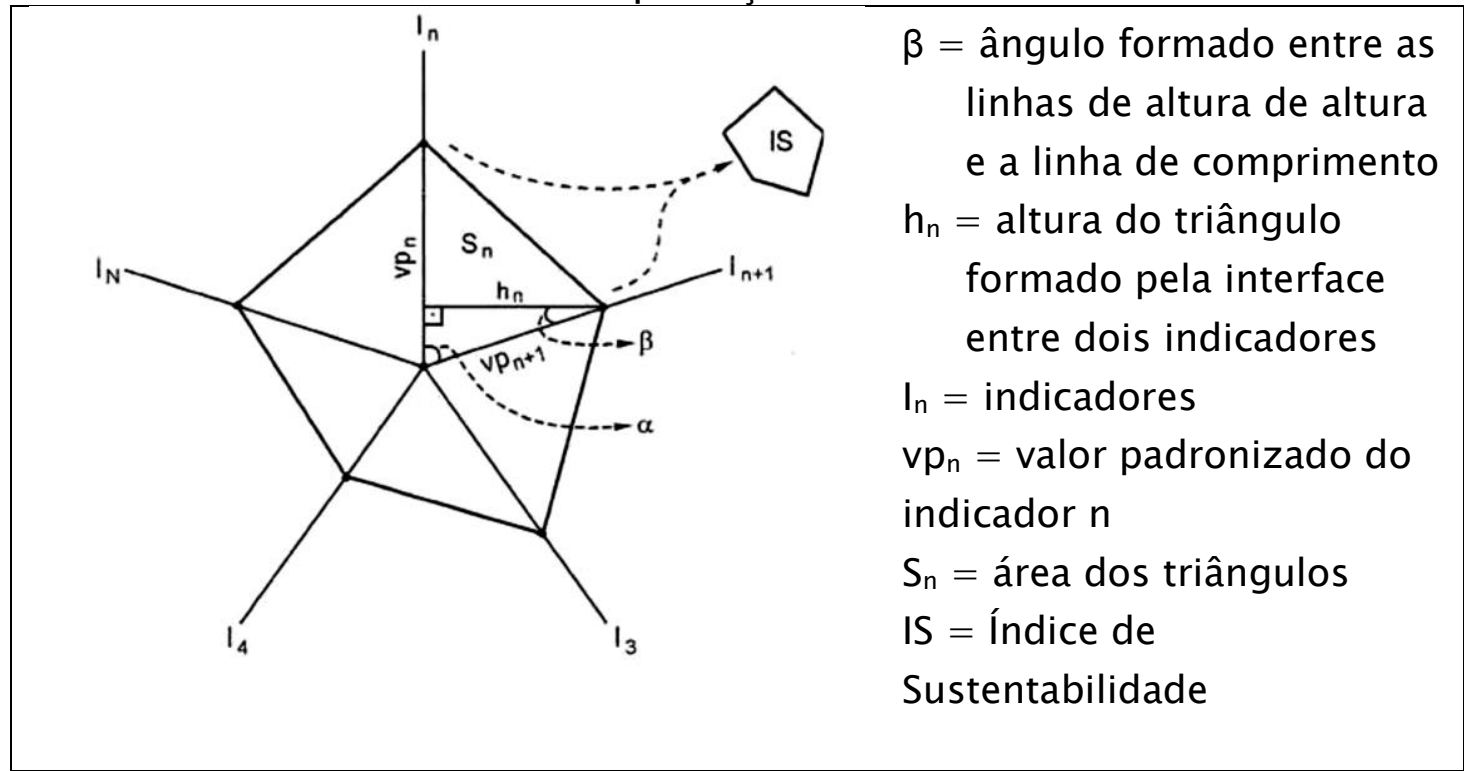

Fonte: Daniel et al. (2001).

Sattler (2013) nos lembra que esse procedimento metodológico, embora possua um caráter visual subjetivo, sua utilização torna-se pertinente, pois favorece a interpretação dos dados e a observação de fenômenos ou correlação de fenômenos que geralmente possuem caráter empírico.

A utilização do desvio-padrão populacional no método foi adotado por Daniel et al. (2001) devido aos indicadores serem selecionados e considerados ideais e/ou 
suficientes de serem utilizados. Nesse caso, os cálculos são empregados em uma população de indicadores. Assim, o método favorece a padronização dos mesmos.

\section{Tratamento e análise dos dados}

O método utilizado para obtenção do índice de sustentabilidade foi proposto por Daniel et al. (2001) e utilizada por Passos (2008), Sattler (2013) e Bomfim (2013). Eles estabeleceram equações matemáticas que têm como produto o gráfico tipo radar onde, por meio do cálculo da área dos triângulos, é possível padronizar os indicadores e/ou dimensões, permitindo uma comparação dinâmica entre eles. Neste estudo, foram estabelecidas os indicadores social, econômica e ambiental.

Inicialmente, realizou-se a padronização dos indicadores em cada dimensão separadamente, pois foram selecionados indicadores diferentes, sendo necessário unificar as unidades de medida e eliminar os efeitos de escalas, assegurando o mesmo peso relativo para cada variável no cálculo do Índice de Sustentabilidade da dimensão. O mesmo processo foi realizado para determinar o Índice de Sustentabilidade do Município de Barra do Choça, sendo, neste caso, as variáveis os IS das dimensões. Para auxiliar nos cálculos do procedimento, utilizou-se a base da planilha eletrônica do Microsoft Excel antecipadamente montada seguindo o passo-a-passo das equações indicadas por Daniel et al. (2001), como se seguem:

$$
\mathrm{vp}_{\mathrm{n}}=\frac{5+\left(\mathrm{x}_{\mathrm{n}}-\bar{x}\right)}{\mathrm{s}}
$$

Onde:

$\mathrm{vp}_{\mathrm{n}}=$ valor padronizado do indicador

$x_{\mathrm{n}}=$ dimensão real do indicador

$\bar{x}=$ valor médio de todos os

indicadores

$\mathrm{S}=$ desvio-padrão de todos os

indicadores

5 = constante para eliminar valores

negativos ou iguais a zero
$\mathrm{O} \mathrm{vp}_{\mathrm{n}}$ igual a zero e negativo, substituir a constante 5 por uma constante calculada menor valor do indicador menos a média dos indicadores, utiliza $\mathrm{o}$ valor maior mais próximo do resultado para obter $u m v p_{n}$ maior que zero e positivo. 


$$
\propto=\frac{360}{\mathrm{~N}} \times \frac{\pi}{180}
$$

Onde:

$\alpha=$ ângulo formado entre as linhas de comprimento de dois indicadores adjacentes

$\mathrm{N}=$ número de indicadores estudados

$\pi=$ valor de pi, adimensional

$$
d_{n}=\sqrt{\left(v p_{n}\right)^{2}+\left(v p_{n+1}\right)^{2}-2 \times\left(v p_{n} \times v p_{n+1}\right) \times \cos \alpha}
$$

Onde:

$\mathrm{d}_{\mathrm{n}}=$ lado desconhecido do triângulo

$\mathrm{vp}_{\mathrm{n}}=$ dimensão padronizado do indicador $\mathrm{n}$

$\mathrm{vp}_{\mathrm{n}+1}=$ dimensão padronizado do indicador $\mathrm{n}+1$

$\cos \alpha=\operatorname{cosseno}$ do ângulo $\alpha$ formado entre os indicadores

$$
p_{n}=\frac{v p_{n}+v p_{n+1}+d_{n}}{2}
$$

Onde:

$\mathrm{p}_{\mathrm{n}}=$ semiperímetro do triângulo $\mathrm{n}$ $v p_{n}, v p_{n+1}$ e $d_{n}=$ lados do triângulo

$$
\beta=180-90-\alpha
$$

Onde:

$\beta=$ ângulo formado entre as linhas de altura e a linha de comprimento

$$
\begin{gathered}
S_{n}=\frac{\left(\left|v p_{n}\right| \times h_{n}\right)}{2} \\
\text { sendo } \quad h_{n}=\cos \beta \times\left|v p_{n+1}\right| \\
\text { então } S_{n}=\frac{\left(v v_{n}|\times \cos \beta \times| v p_{n+1} \mid\right)}{2}
\end{gathered}
$$

Onde:

$\beta=$ ângulo formado entre as linhas de altura de altura e a linha de comprimento

$\mathrm{h}_{\mathrm{n}}=$ altura do triângulo formado pela interface entre dois indicadores

$\mathrm{vp}_{\mathrm{n}}=$ valor padronizado do indicador $\mathrm{n}$

$\mathrm{S}_{\mathrm{n}}=$ área dos triângulos 


$$
I S=\sum_{n=1}^{N} S_{n}
$$

Onde:

IS = índice de sustentabilidade

$\mathrm{N}=$ número de indicadores

$\mathrm{S}_{\mathrm{n}}=$ área dos triângulos

Para análise dos resultados, utilizou-se como parâmetro o corolário da sustentabilidade, no qual são atribuídos pesos de 0 a 1 , de acordo com o nível de desempenho do indicador ou da dimensão (Quadro 2) e os níveis de sustentabilidade (Quadro 3), estabelecidos pelo PNUD, citados por Sattler (2013).

\section{Quadro 2. Corolário da sustentabilidade}

\begin{tabular}{|l|l|}
\hline \multicolumn{1}{|c|}{ Peso/Nível } & \multicolumn{1}{c|}{ Desempenho } \\
\hline $0 \leq$ IS $\leq 0,25$ & Insustentável \\
$0,25 \leq$ IS $\leq 0,50$ & Intermediário \\
$0,50 \leq$ IS $\leq 0,75$ & Quase Sustentável \\
$0,75 \leq$ IS $\leq 1$ & Sustentável \\
\hline
\end{tabular}

Fonte: Bomfim (2013).

Quadro 3. Níveis de sustentabilidade

\begin{tabular}{|cl|}
\hline Valores & Nível \\
\hline 0,0 a 0,3 & Crítico \\
0,31 a 0,50 & Baixo \\
0,51 a 0,70 & Regular \\
0,71 a 0,90 & Bom \\
0,91 a 1,00 & Ótimo \\
\hline
\end{tabular}

Fonte: Sattler (2013).

\section{Resultados e Discussão}

$\mathrm{Na}$ dimensão social, foram selecionados indicadores a partir do PNUD (2013), a saber: $I_{n 1}=$ Vulneráveis à pobreza (\%), $I_{n 2}=$ Pobres (\%) e $\mathrm{I}_{\mathrm{n} 3}=$ Pessoas de 18 anos ou mais sem Fundamental completo e em ocupação informal (\%). O tratamento dos dados indicou um Índice de Sustentabilidade para a Dimensão Social (ISDS) de 1,025 (Tabela 1, 


\section{Gráfico 1).}

Redes (St. Cruz Sul, Online), v. 21, n² 2, p. 87 - 106, maio/ago. 2016103 
Tabela 1. Índice de sustentabilidade da dimensão social

\begin{tabular}{ccccc}
\hline Valor do Indicador & $\mathrm{Vp}_{\mathrm{n}}$ & $\mathrm{d}_{\mathrm{n}}$ & $\mathrm{P}_{\mathrm{n}}$ & $\mathrm{S}$ \\
\hline $\mathrm{I}_{\mathrm{n} 1}=63,44$ & 2,711 & 4,779 & 5,149 & 0,215 \\
$\mathrm{I}_{\mathrm{n} 2}=31,84$ & 1,029 & 3,439 & 3,638 & 0,223 \\
$\mathrm{I}_{\mathrm{n} 3}=65,24$ & 2,807 & 3,347 & 3,544 & 0,587 \\
\hline \multicolumn{7}{c}{} \\
\hline
\end{tabular}

Fonte: Dados da pesquisa.

Gráfico1. Representação da área ocupada dos indicadores da dimensão social

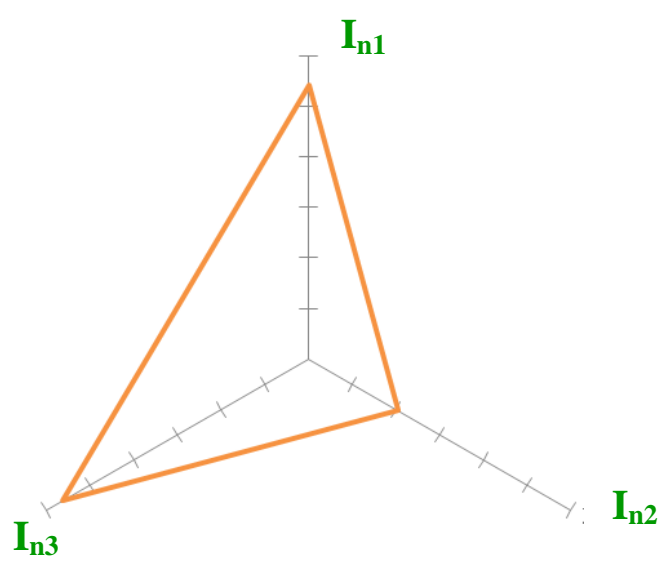

Fonte: Dados da pesquisa.

Observa-se que a relação entre os indicadores vulneráveis à pobreza $\left(I_{n 1}\right)$ e o número de pessoas de 18 anos ou mais sem Fundamental completo e em ocupação informal $\left(I_{n 3}\right)$ é proporcional, o que indica a necessidade de uma ação no campo educacional para melhor qualificação e elevação da renda dos trabalhadores, pois, em 2010 , o município teve mais de $60 \%$ de indivíduos vulneráveis à pobreza (PNUD, 2013). O que destoa do indicador do número de pobres no município e "falseia" esse dado, pois, ele visto isolado eleva a qualidade de vida do município o que provavelmente faz com que o seu Índice de Sustentabilidade seja positivo. Lembrando que muitos dos proprietários das áreas de café não residem em Barra do Choça, mas grande parte dos catadores de café sim.

Nesse sentido, Soares e Rocha (2010, p. 144) apontam que " 49,6 $\%$ dos donos de terras residem em outros municípios, destes, a grande maioria, 39 \% moram em Vitória da Conquista, maior cidade da região Sudoeste e terceira maior cidade da Bahia, que polariza a região como 
um todo [...]", o que marca a relação de poder entre os municípios da região Sudoeste. Quanto aos catadores as autoras abordam o seguinte:

mas a grande maioria reside no município e fica ociosa nos meses da entressafra, pois a oferta do trabalho diminui de forma abrupta, Nesse período, constata-se o aumento do número de "pedintes" e dos problemas sociais, que assolam de maneira considerável a população mais carente, aumentando a situação de risco e colocando as pessoas numa condição de maior vulnerabilidade. Isto, porque a maioria da população sobrevive do trabalho na cafeicultura, que é considerada importante na região, pois consegue amenizar a situação da pobreza durante um bom período do ano (SOARES; ROCHA, 2010, p. 145).

Corroborando Rocha (2011) diz que há um ciclo de renda entre a safra e a entressafra do café, enfatizando que:

[...] uma grande parcela da população que vive em condições precárias economicamente. Porém como é de conhecimento da população local, não existiam programas sociais voltados para as pessoas menos favorecidas economicamente, mas sim uma política pautada no assistencialismo (ROCHA, 2011, p. 71).

Essa relação da renda com o indicador de pobreza nos leva à dimensão econômica, na qual foram observados os seguintes indicadores: $\ln _{\mathrm{n} 1}=$ Renda per capita $(\mathrm{R} \$), \ln _{\mathrm{n} 2}=$ Financiamentos Bancários para Agricultura $(R \$ 1,0)$ e $I_{n 3}=$ Produção agrícola $(T)$, disponíveis pela SEI $(2012,2013)$ e PNUD (2013). O tratamento dos dados indicou um Índice de Sustentabilidade para a Dimensão Econômica - ISDE de 0,532 (Tabela 2, Gráfico 2).

Tabela 2. Índice de sustentabilidade da dimensão econômica

\begin{tabular}{ccccc}
\hline Valor do Indicador & $\mathbf{v p}_{\mathbf{n}}$ & $\mathbf{d}_{\mathbf{n}}$ & $\mathbf{P}_{\mathbf{n}}$ & $\mathrm{S}$ \\
\hline $\mathrm{I}_{\mathrm{n} 1}=266,13$ & 1,039 & 1,810 & 1,950 & 0,223 \\
$\mathrm{I}_{\mathrm{n} 2}=10.713 .012,49$ & 2,777 & 3,426 & 3,627 & 0,225 \\
$\mathrm{I}_{\mathrm{n} 3}=76.715$ & 1,051 & 3,417 & 3,617 & 0,084 \\
\hline
\end{tabular}

Fonte: Dados da pesquisa. 
Gráfico 2. Representação da área ocupada dos indicadores da dimensão econômica

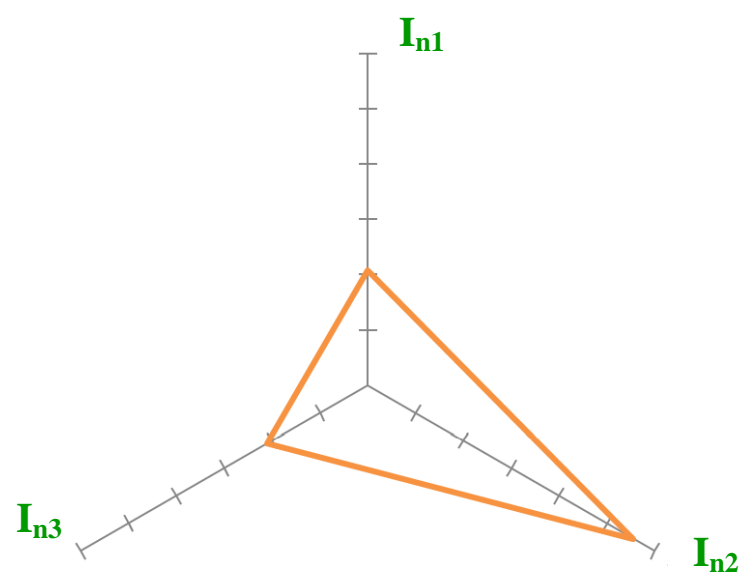

Fonte: Dados da pesquisa.

Observa-se, no gráfico 2, que o indicador financiamentos bancários para agricultura está em disparidade com os indicadores de produção agrícola e renda per capita, ao tempo em que há uma estabilidade dos indicadores um e três. Como Rocha (2011) aponta uma crise na atividade cafeeira, o que se pode indagar é que esses financiamentos foram direcionados a pagamento das dívidas agrícolas decorrentes dessa crise ou, como aponta a autora, que:

os investimentos na produtividade foram resultados de empréstimos concedidos pelos programas de governo com a finalidade de fixar as pessoas no campo. Porém é importante salientar que tais empréstimos não foram suficientes para garantir a fixação desses habitantes, como revela a tabela 03, em 2010 houve uma diminuição da população rural passando de 23.097 para apenas 12.381. Assim, podemos afirmar que houve um grande êxodo rural de quase 50 \% (ROCHA, 2011 , p. 38).

No entanto, dados da SEI $(2012,2013)$ e PNUD (2013) revelam que, mesmo com a crise, a renda per capita do Município de Barra do Choça passou de R\$71,75 em 2000 para 266,13 em 2010.

Por outro lado, Soares e Rocha (2010, p. 147) dizem que há um domínio nos financiamentos por parte dos grandes proprietários levando os pequenos, para alcançarem estes investimentos, a se agruparem em associações, onde as autoras registram a existência de 
18 associações agrícolas e lembram que a "produção agrícola é sustentada na ótica da atividade agrícola destinada para o comércio de exportação", o que agrega um maior valor à terra.

Já na dimensão ambiental, selecionou-se os indicadores: $I_{n 1}=$ Pluviosidade anual $(\mathrm{mm}), \mathrm{I}_{\mathrm{n} 2}=$ Temperatura média anual $\left({ }^{\circ} \mathrm{C}\right)$ e $\ln _{\mathrm{n} 3}=$ Consumo de água $\left(\mathrm{m}^{3}\right)$, disponíveis pela SEI $(2012,2013)$. O tratamento dos dados indicou um Índice de Sustentabilidade para a Dimensão Ambiental - ISDA de 0,501 (Tabela 3, Gráfico 3).

Tabela 3. Índice de sustentabilidade da dimensão ambiental

\begin{tabular}{lcccc}
\hline & $\mathbf{v p}_{\mathrm{n}}$ & $\mathbf{d}_{\mathrm{n}}$ & $\mathbf{P}_{\mathrm{n}}$ & $\mathrm{S}$ \\
\hline $\mathrm{I}_{\mathrm{n} 1}=733,9$ & 1,003 & 3,351 & 3,545 & 0,078 \\
$\mathrm{I}_{\mathrm{n} 2}=20,2$ & 1,002 & 3,350 & 3,544 & 0,211 \\
$I_{\mathrm{n} 3}=986.921$ & 2,735 & 1,737 & 1,871 & 0,212 \\
\hline \multicolumn{5}{c}{ ISDA $=0,501$} \\
\hline
\end{tabular}

Fonte: Dados da pesquisa. 
Gráfico 3. Representação da área ocupada dos indicadores da dimensão ambiental

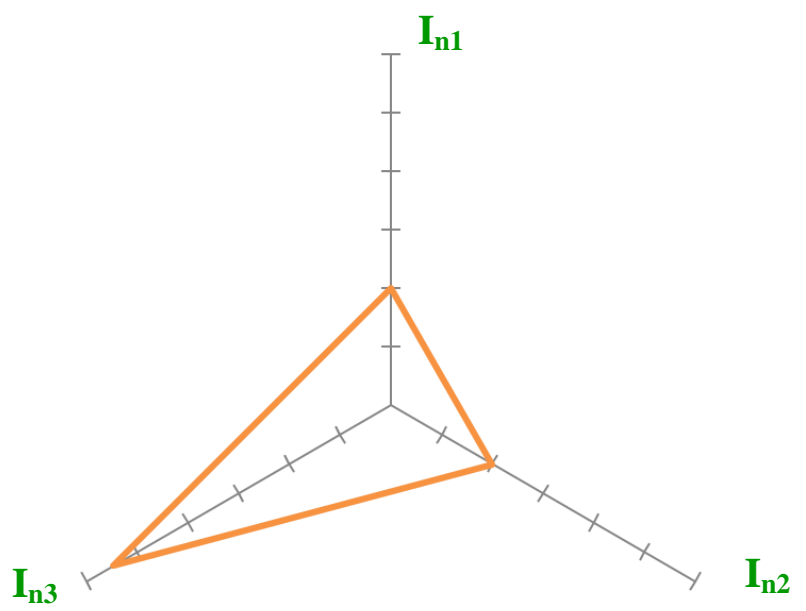

Fonte: Dados da pesquisa.

No gráfico 3, pode-se perceber uma estabilidade entre a pluviosidade anual e a temperatura média anual, o que marca o clima agradável do município, mas o aumento no consumo de água não é proporcional ao crescimento populacional, pois, neste período, ocorre um desaceleramento populacional no município (ROCHA, 2011).

Lembrando que as barragens que abastecem a cidade e alguns municípios vizinhos sofrem influência diretamente da pluviosidade e da temperatura, pois uma menor pluviosidade e maior temperatura, como aponta Sattler (2013), têm uma relação com a vazão das nascentes, ocasionado em menor produção de água. Observa-se, também, que a região tem enfrentado períodos cada vez maiores de seca, que coincide com o desmatamento ocorrido a partir da década de 1970. Em relação à seca, Rocha (2011) relata que, entre 2003/2005, ocorreu um período de seca que assolou a região, provocando perda de grãos, queda na produção e desemprego no município.

As altas temperaturas e pouca pluviosidade anual levam ambientalistas e associações a movimentarem a população e o poder público do município sobre as questões ambientais, haja vista que, após a devastação ocorrida pela produção cafeeira, havia, neste momento, uma invasão da monocultura do eucalipto, seja como prática de reflorestamento ou produção econômica. 
Rocha $(2011$, p. $72 ; 73)$ relata que:

[...] a implantação da lavoura cafeeira em Barra do Choça, é a ocorrência de mudanças no espaço do campo referente as questões relacionadas ao meio ambiente, pois estas eram relegadas ao último plano e por vezes, sequer eram lembradas, pois o crescimento econômico estava atrelado à destruição das matas virgens para o plantio de café. Sendo que o roteiro seguido era: derrubada de mata virgem de forma manual ou com trator esteira, seguindo de queimadas, aração e gradagem. [...] a monocultura cafeeira trouxe consigo os primeiros e mais graves problemas ambientais para o município. Mas no inicio da implantação do café não restavam alternativas para que o município elevasse sua renda, assim, o "pacote tecnológico", foi facilmente aceito pelos produtores sem que apontassem posicionamento contrário. Até porque naquele período as leis ambientais não influenciavam tanto, não tinham grande repercussão no Brasil, sobretudo nas pequenas cidades interioranas.

Assim, a partir de 2010, ocorrem as discussões em prol dessas questões que concorrem para a criação da RPPN do Rio dos Monos, principal nascente que abastece Água Fria I e II e do Projeto de Lei que dispõe sobre o plantio e replantio de eucalipto ou outras espécies exóticas.

Visto cada dimensão separadamente, os dados são trabalhados em conjunto (dimensões econômica, social e ambiental) para a determinação do Índice de Sustentabilidade do Município de Barra do Choça $(0,762)$, e estão representados na Tabela 4 , no Quadro 4 e no Gráfico 4.

Tabela 4. Índice de sustentabilidade do Município de Barra do Choça

\begin{tabular}{ccccc}
\hline & $\mathbf{V p}_{\mathrm{n}}$ & $\mathbf{d}_{\mathrm{n}}$ & $\mathbf{P}_{\mathrm{n}}$ & $\mathrm{S}$ \\
\hline ISDS $I_{\mathrm{n} 1}=1,025$ & 3,058 & 3,857 & 4,095 & 0,326 \\
ISDE $I_{\mathrm{n} 2}=0,532$ & 1,381 & 2,301 & 2,479 & 0,136 \\
ISDA $I_{\mathrm{n} 3}=0,501$ & 1,276 & 3,935 & 4,187 & 0,301 \\
\hline \multicolumn{7}{c}{ IS $=0,762$} \\
\hline
\end{tabular}

Fonte: Dados da pesquisa.

Gráfico 4. Representação da área ocupada pelos índices de sustentabilidade das dimensões econômica, social e ambiental 
Índice de sustentabilidade do Município de Barra do Choça-BA

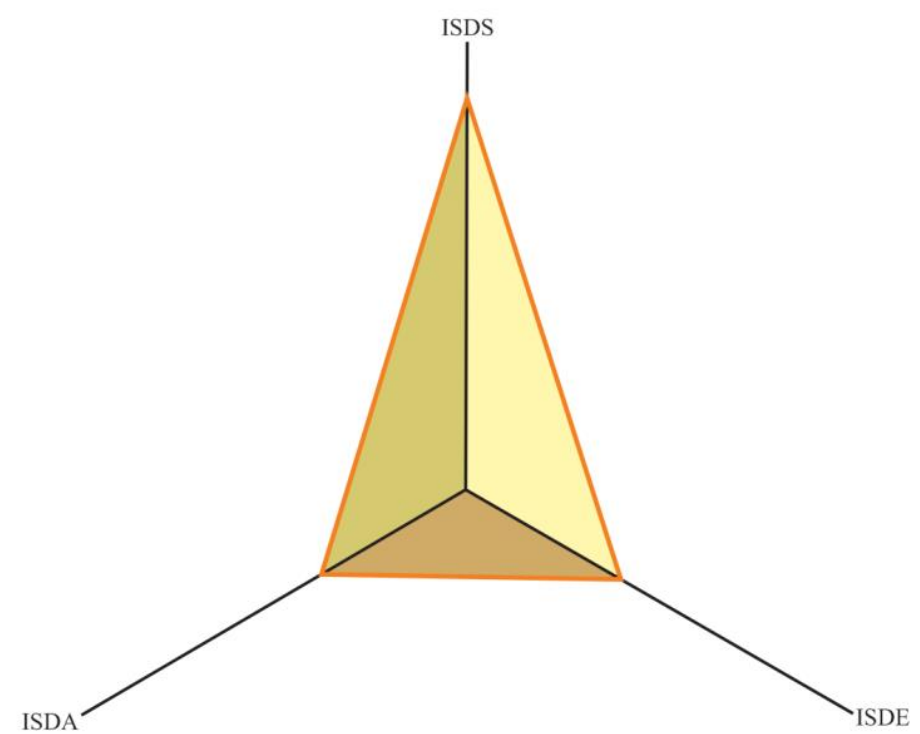

Fonte: Dados da pesquisa.

Redes (St. Cruz Sul, Online), v. 21, n² 2, p. 87 - 106, maio/ago. 2016110 
Quadro 4. Corolário e nível de sustentabilidade do Município de Barra do Choça

\begin{tabular}{|c|c|c|c|c|c|}
\hline Peso/Nível & Desempenho & Índice & Dimensão & Valores & Nível \\
\hline $0 \leq \mathrm{IS} \leq 0,25$ & Insustentável & & & 0,0 a 0,3 & Crítico \\
\hline $\begin{array}{l}0,25 \leq \mathrm{IS} \leq \\
0,50\end{array}$ & Intermediário & & & $\begin{array}{l}0,31 \mathrm{a} \\
0,50\end{array}$ & Baixo \\
\hline \multirow{2}{*}{$\begin{array}{l}0,50 \leq \mathrm{IS} \leq \\
0,75\end{array}$} & \multirow{2}{*}{$\begin{array}{l}\text { Quase } \\
\text { Sustentável }\end{array}$} & 0,53 & Econômica & $0,51 \mathrm{a}$ & \multirow{2}{*}{ Regular } \\
\hline & & 0,58 & Ambiental & 0,70 & \\
\hline \multirow{2}{*}{$0,75 \leq \mathrm{IS} \leq 1$} & \multirow{2}{*}{ Sustentável } & 0,76 & as 3 juntas & $\begin{array}{l}0,71 \mathrm{a} \\
0,90\end{array}$ & Bom \\
\hline & & 1,025 & Social & $\begin{array}{l}0,91 \mathrm{a} \\
1,00\end{array}$ & Ótimo \\
\hline
\end{tabular}

Fonte: Dados da pesquisa em relação a Sattler (2013) e Bonfim (2013).

Analisando cada dimensão isoladamente, os dados demonstram uma harmonia entre as dimensões econômica e ambiental e que a dimensão social apresentou um maior índice de sustentabilidade, representando o dobro de cada um dos outros dois índices, elevando o índice geral a uma margem inicial de sustentabilidade. No entanto, como foi visto anteriormente, fazem-se necessários outros estudos para melhor compreender a dinâmica entre as dimensões para confirmar ou não os resultados deste estudo, que aponta que a sustentabilidade do Município de Barra do Choça se equilibra por meio da dimensão social. Resultado parecido foi encontrado por Sattler (2013) em estudo com metodologia semelhante, mas com o uso de outros indicadores, no entanto enfocando as mesmas dimensões, que aponta que a avaliação dos dados no gráfico foi feita a partir da simetria entre os índices, assim, a maior sustentabilidade se dá pela maior simetria do polígono.

\section{Considerações finais}

A metodologia desenvolvida neste estudo possibilitou uma melhor clareza na representação dos resultados, que envolveu a mensuração de sustentabilidade com diferentes indicadores e uma facilidade de emprego da ferramenta e modelo para determinar o Índice de Sustentabilidade, assim, mostra-se uma metodologia de fácil utilização.

Os índices das dimensões revelaram que a dimensão social obteve melhor desempenho que as dimensões econômica e ambiental, nas quais seus indicadores apontam resultados semelhantes. Assim, as 
dimensões econômica e ambiental apresentaram índices bons e a dimensão social apresentou índice considerado sustentável. E o Instituto de Sustentabilidade - IS indica, no geral, um bom desempenho do município em direção à sustentabilidade.

Considerando a discussão sobre a sustentabilidade, o desenvolvimento e as inquietações por alguns indicadores oficiais não expressarem a realidade local, espera-se que o estudo possa alertar quanto à sustentabilidade local e embasar as tomadas de decisões para melhorar a sustentabilidade municipal.

Por fim, a investigação demonstrou a relevância da metodologia no conhecimento do Instituto de Sustentabilidade - IS como fator a ser observado nas decisões e no emprego de políticas públicas. 


\section{REFERÊNCIAS}

AMORIM, J. Barra do Choça: Câmara Municipal aprova Projeto de Lei que restringe o plantio do Eucalipto no município 18 de dezembro de 2012. Disponível em: <http://blogdojorgeamorim.com.br/barra-do-chocacamara-municipal-aprova-projeto-de-lei-que-restringe-o-plantio-doeucalipto-no-municipio/>. Acesso em: 08 nov. 2014.

AMORIM, R. S. O destino das águas das barragens de Barra do Choça, Bahia. 2014. 56p. Monografia (Graduação em Geografia) - Universidade Estadual do Sudoeste da Bahia, Vitória da Conquista, 2014.

BOMFIM, E. de O. Sustentabilidade hidroambiental de áreas de captações de nascentes na bacia hidrográfica do Rio Gramame-PB. 2013. 129p. Dissertação (Mestrado em Engenharia Urbana e Ambiental) Universidade Federal da Paraíba, João Pessoa, 2013.

BONFIM, D. A.; SANTOS, J. O.; SAMPAIO, R. J.; SILVA JUNIOR, M. F. da. Considerações sobre as mudanças climáticas e os impactos na subbacia do rio Catolé para o município de Vitória da Conquista-Bahia. Rev. Eletrônica Mestr. Educ., v. 29, p. 1-16, jul./dez. 2012.

DANIEL, O.; COUTO, L.; SILVA, E.; GARCIA, R.; JUCKSCH, I. Alternativa a um método para determinação de um índice de sustentabilidade. Revista Árvore (Impresso), Viçosa, v. 25, n.4, p. 455-462, 2001.

IBGE. Barra do Choça. Disponível em: $<$ http: / / cidades.ibge.gov.br/xtras/perfil.php?lang $=\&$ codmun $=290290 \&$ search=bahia $\mid$ barra-do-choca $>$. Acesso em: 22 out. 2014.

OlIVEIRA, J. T. de.; MOREAU, A. M. S. dos S.; MENEZES, A. A.; PAIVA, A. de Q.; MESSIAS, T. Modificações ambientais e sócio-econômicas decorrentes do desenvolvimento da cafeicultura em Barra do Choça, Bahia. Bahia Agríc., v. 8, n. 1, nov. 2007.

PASSOS, H. D. B. Indicadores de sustentabilidade: uma discussão teórico metodológica para sistemas agroflorestais no Sul da Bahia. 2008. $241 \mathrm{p}$. 
Dissertação (Mestrado) - Universidade Estadual de Santa Cruz, Ilhéus, 2008.

PASSOS, H. D. B. Indicadores de sustentabilidade: uma discussão teórico metodológica aplicada a sistemas agroflorestais no Sul da Bahia. Embrapa. Cd Agro. [2010]. Disponível em:

<http://www.sct.embrapa.br/cdagro/tema04/04tema23.pdf $>$. Acesso em: 11 nov. 2014.

PERUZZO, C. M. K.; VOLPATO, M. de O. Conceitos de comunidade, local e região: inter-relações e diferenças. In: COLÓQUIO BINACIONAL BRASIL-MÉXICO DE CIÊNCIAS DA COMUNICAÇÃO, 2., 2009. Anais... São Paulo - Brasil

PROGRAMA DAS NAÇÕES UNIDAS PARA O DESENVOLVIMENTO (PNUD). Fundação João Pinheiro. Instituto de Pesquisa Econômica Aplicada (IPEA) Perfil municipal. Anagé - BA. In: Atlas do desenvolvimento humano no Brasil 2013. Disponível em: $<$ http://www.atlasbrasil.org.br/2013/pt/perfil/anage_ba $>$. Acesso em: 22 out. 2014.

REED, M. S.; FRASER, E. D. G.; DOUGILL, A J. An adaptive learning process for developing and applying sustainability indicators with local communities. ScienceDirect, p. 406-418, Jan 2006.

DOI:10.1016/j.ecolecon.2005.11.008.

ROCHA, L. O. Transformações na cidade de Barra do Choça/BA após a implantação da cafeicultura: uma análise da relação cidade-campo. 2011. 137f. Dissertação (Mestrado em Geografia) - Instituto de Geociências, Universidade Federal da Bahia, Salvador, 2011.

SATTLER, M. A. Sustentabilidade de sistemas agroflorestais na Região do Caparaó - ES. 2013. 108f. Tese (Doutorado - Produção Vegetal) Universidade Estadual do Norte Fluminense Darcy Ribeiro, Centro de Ciências e Tecnologias Agropecuárias. Campos dos Goytacazes, RJ, 2013. 
SEBRAE; CONFEDERAÇÃO NACIONAL DOS MUNICÍPIOS (CNM). Barra do Choca-BA economia diversificada. 2010-2014. Disponível em: $<$ http:/ /www.portaldodesenvolvimento.org.br/barra-do-choca-baeconomia-diversificada/>. Acesso em: 08 nov. 2014.

SOARES, V. de O.; ROCHA, L. O. A evolução da estrutura agrária do município de Barra do Choça - BA. Revista NERA, Presidente Prudente, ano 13, n. 17, p. 131-149, jul./dez. 2010.

SUPERINTENDÊNCIA DE ESTUDOS ECONÔMICOS E SOCIAIS DA BAHIA (SEI). Estatísticas dos Municípios Baianos [recurso eletrônico], Salvador: SEI, v. 4, n. 1, p. 55-72, 2012.

SUPERINTENDÊNCIA DE ESTUDOS ECONÔMICOS E SOCIAIS DA BAHIA (SEI). Território de identidade $\mathrm{n}^{\circ}$ 20: Vitória da Conquista. In:

Estatísticas dos Municípios Baianos [recurso eletrônico], Salvador: SEl, v. 4, n. 1, p. 55-72, 2013. ISSN 1519-4124.

TRIBUNA FEIRENSE. As 50 maiores cidades da Bahia, em população. Feira de Santana, terça-feira, 31 ago. 2013b. Disponível em: <http://www.tribunafeirense.com.br/noticias/4899/as-50-menorescidades-da-bahia-em-populacao >. Acesso em: 08 nov. 2014.

TRIBUNA FEIRENSE. As 50 menores cidades da Bahia, em população. Feira de Santana, terça-feira, 31 ago. 2013a. Disponível em: <http://www.tribunafeirense.com.br/noticias/4899/as-50-menorescidades-da-bahia-em-populacao >. Acesso em: 18 nov. 2014. 
Submetido em 29/09/2015

Aprovado em 09/04/2016

\section{Sobre os autores}

\section{Celeste Dias Amorim}

Doutoranda em Desenvolvimento e Meio Ambiente pela UESC. Mestre em Ciências Ambientais pela UESB. Bolsista da FAPESB.

E-mail: celamorim@gmail.com

\section{George Nathan Souza Brito}

Doutorando em Desenvolvimento e Meio Ambiente, Prodema/UESC. Mestre em Agronomia, UFC. Engenheiro Agrônomo. Prof. Assistente da UESC, Ilhéus, Bahia, Brasil. E-mail: georgenathan@hotmail.com

\section{Milton Ferreira da Silva Júnior}

Doutor em Educação pela UFBA. Mestre em Sociologia Rural pela UFRG. Docente da UFSB. Docente do Programa da Rede PRODEMA/UESC (Mestrado e Doutorado). Ilhéus, Bahia, Brasil.

E-mail: notlimf@gmail.com 